\title{
DESIGN AND ANALYSIS OF HANDICAPPED STEERING TRICYCLE
}

\author{
Gaurav Singh Parihar', Sanjay Singh Azad ${ }^{2}$ \\ ${ }^{1}$ U.G. Student, Department of Mechanical Engineering, Institute of Information Technology and Management, \\ Gwalior, M.P., India \\ ${ }^{2}$ Technical Head, Cadd Plus Training Services, Gwalior, M.P., India
}

\begin{abstract}
Conventional tricycles for handicapped require a lot of human effort to operate. They generally come with separate arrangements for providing motion and giving direction to the vehicle. These separate arrangements cause asymmetric use of hands and this results in discomfort of the rider. To alleviate this discomfort, a new arrangement which is mechanically more efficient than the conventional handicapped tricycle has been introduced, contains a single unit for providing motion and giving direction to the tricycle. Push and Pull motion of the steering results in forward and backward motion of the chair, while rotational motion of the same gives direction to the chair. In this paper, structural analysis is performed on the handicapped steering tricycle. Modelling is done on Solidworks 14 and ANSYS Workbench 15 is used to perform structural analysis.
\end{abstract}

Keywords:- Lever-propelled wheelchair, Handicapped Steering Tricycle, Structural Analysis, and Design optimization.

\section{INTRODUCTION}

About $1.85 \%$ of the total world's population, that is 7.1 billion, 130 million need wheelchairs or handicapped tricycles. Out of these 130 million, nearly 120 million population live in developing countries. Developed countries easily fulfill the demands of handicapped vehicles because of better technology and strong economy. On the other hand, in developing countries, due to limited resources in terms of economy and technology, the handicapped vehicles are required to be made cheaper, durable, comfortable, and efficient. There are cheaper materials available which are durable too, but the main area of concerns are comfortability and efficiency.

Conventional handicapped tricycles are tedious because of their asymmetrical mechanisms and inefficient drive systems. Handicapped steering tricycle is a better substitute because of its better motion and steering unit and drive system.

\subsection{Handicapped Steering Tricycle}

Handicapped Steering Tricycle uses a crank-lever mechanism for its forward and backward motion. It is equipped with a small diameter steering wheel which can provide both: direction and motion to the tricycle. By pushing and pulling this steering, the rider can move the tricycle and by rotating the steering the rider can direct the tricycle. A braking lever is provided just beneath the steering wheel to apply the brakes.

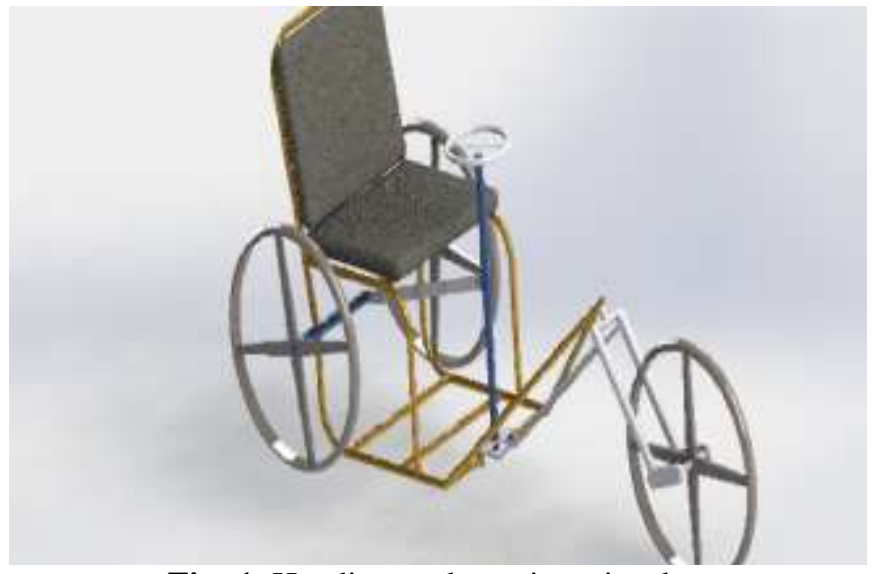

Fig -1: Handicapped steering tricycle

\subsection{Materials Used and Dimensions}

Due to their higher strength to weight ratios, better machinability, low cost and durability, metals are used for manufacturing these tricycles. They are easily available and they can be used specifically for a desired mechanical or physical property.

The metal used to assign to all the parts except chassis is: Stainless Steel 304. Material properties are given in Table-1.

Table -1: Material properties of Stainless Steel (SS-304)

\begin{tabular}{|l|l|l|}
\hline S. no. & Material Property & Value \\
\hline 1. & Density & $8000 \mathrm{~kg} / \mathrm{m}^{3}$ \\
\hline 2. & Young's Modulus (E) & $193 \mathrm{GPa}$ \\
\hline 3. & Poisson's ratio & 0.27 \\
\hline 4. & Tensile Strength & $500 \mathrm{MPa}$ \\
\hline 5. & $\begin{array}{l}\text { Coefficient of Thermal } \\
\text { Expansion }\end{array}$ & $17 \times 10^{-6} /{ }^{\circ} \mathrm{C}$ \\
\hline
\end{tabular}


Chassis is made by assigning the material: Structural Steel. It is a very common material, used for constructing frames of automobiles. Foam is used for seat. Material properties of SS-304 are given in Table-2.

Table-2: Material properties of Structural Steel

\begin{tabular}{|l|l|l|}
\hline S. no. & Material Property & Value \\
\hline 1. & Density & $7850 \mathrm{~kg} / \mathrm{m}^{3}$ \\
\hline 2. & Young's Modulus (E) & $210 \mathrm{GPa}$ \\
\hline 3. & Poisson's ratio & 0.3 \\
\hline 4. & Tensile Yield Strength & $210 \mathrm{MPa}$ \\
\hline 5. & $\begin{array}{l}\text { Coefficient of Thermal } \\
\text { Expansion }\end{array}$ & $12 \times 10^{-6} /{ }^{\circ} \mathrm{C}$ \\
\hline
\end{tabular}

Dimensions of Handicapped Steering cycle are given in Table-3.

Table-3: Dimensions of Handicapped steering cycle

\begin{tabular}{|c|c|c|}
\hline S. no. & Part & $\begin{array}{l}\text { Dimension } \\
\text { (in inches) }\end{array}$ \\
\hline 1. & Diameter of pipe & 2.5 \\
\hline 2. & Diameter of wheel & 50 \\
\hline 3. & Distance between rear wheels & 85 \\
\hline 4. & Height of seat from the ground & 80 \\
\hline 5. & Length and width of seat & 70 \\
\hline 6. & Height of axle from the ground & 25 \\
\hline 7. & Width of the chair bottom & 80 \\
\hline 8. & $\begin{array}{l}\text { Length of rod supporting front } \\
\text { wheel }\end{array}$ & 133 \\
\hline 9. & $\begin{array}{l}\text { Angle of the rod supporting } \\
\text { front wheel }\end{array}$ & $43^{\circ}$ \\
\hline
\end{tabular}

\subsection{Solidworks Model}

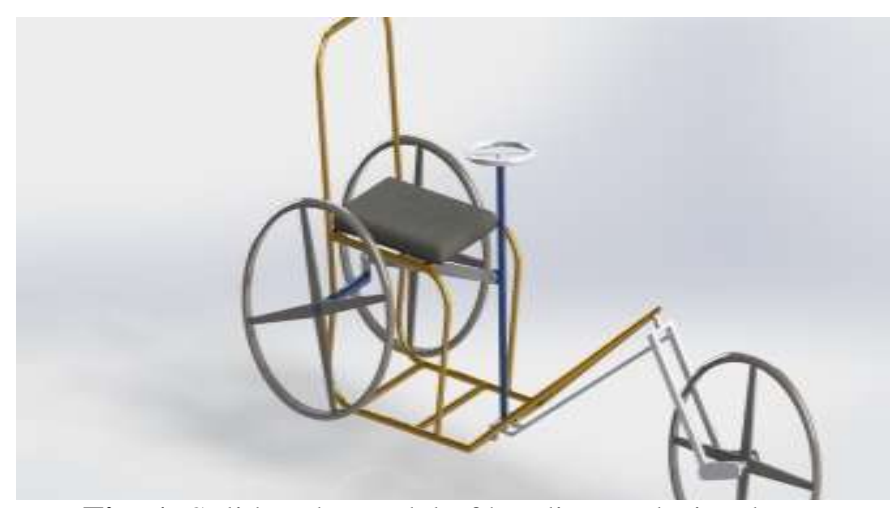

Fig -1: Solidworks model of handicapped tricycle.

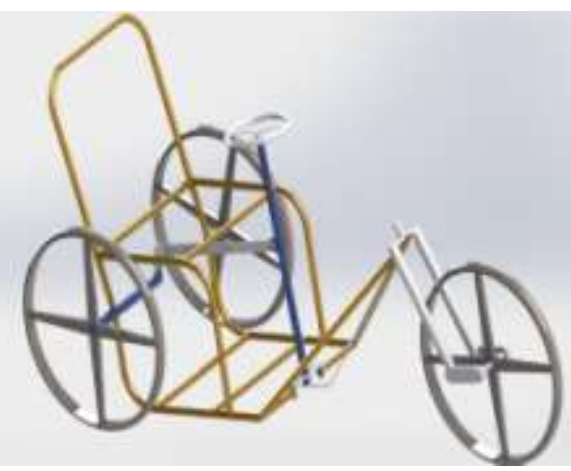

Fig -2: Handicapped tricycle without seat.

\section{ANSYS RESULTS}

ANSYS Workbench 15 is one of best Finite Element Analysis software in the simulation industry. Structural analysis is performed on the tricycle. To make the problem easier, analysis is done only on the chassis rather than the whole cycle. The chassis is fixed at point A, assuming the wheels to be fixed, and a load of $1000 \mathrm{~N}$ is applied in downward direction from the bottom of the seat. $1000 \mathrm{~N}$ is approximately $100 \mathrm{kgs}$ i.e.; weight of rider and the cycle. ANSYS results are shown in Figures 4, and 5.
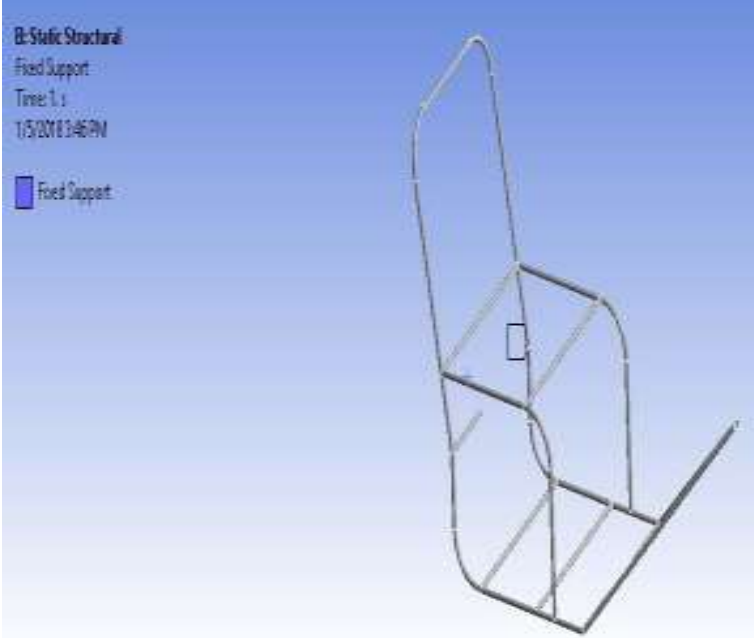

reg -s: support allu r raction

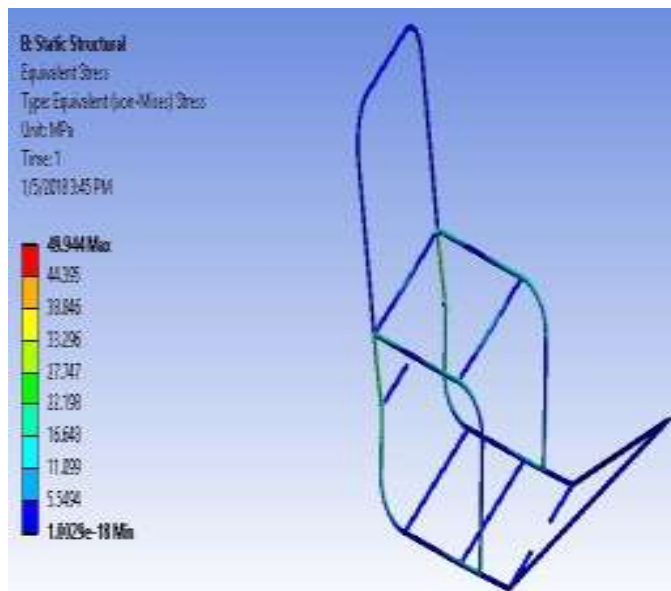

Fig -4: Equivalent stress in tricycle at load $1000 \mathrm{~N}$. 
Equivalent stress at the load $1000 \mathrm{~N}$, in tricycle is found to be nearly $50 \mathrm{MPa}$. Tensile Yield strength of Structural Steel is $210 \mathrm{MPa}$, so the chassis is safe.

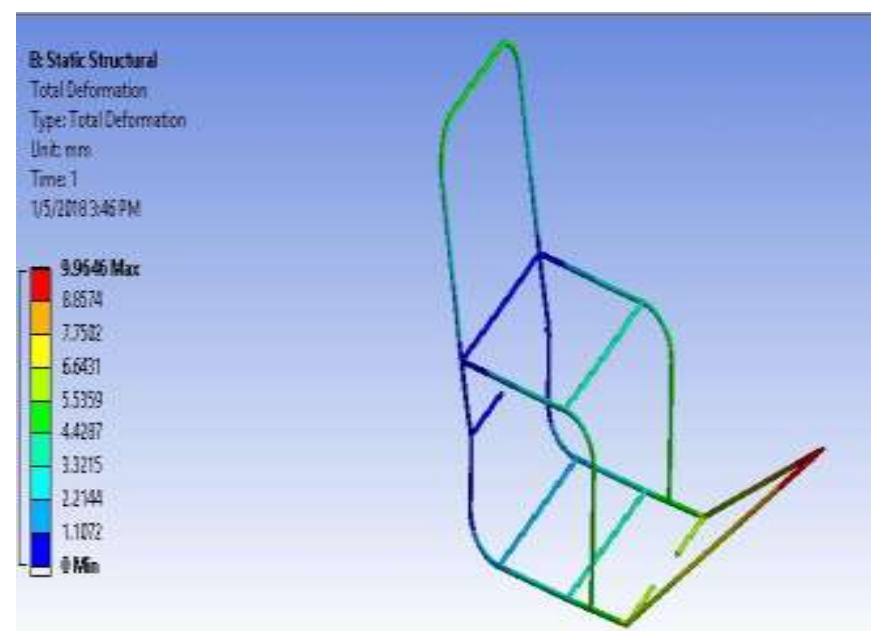

Fig -5: Total deformation in tricycle at load $1000 \mathrm{~N}$.

Total deformation in the chassis is found to be $1.15 \mathrm{~mm}$. It is mostly concentrated near the seat.

\section{CONCLUSION}

Results from structural analysis of this handicapped steering cycle shows that the stress and deformation is within the limits. If it is compared with conventional handicapped cycles then it is found to be easy to maneuver, control, and move. It is driven with subtle and periodic motion of hands, and less power is required by the rider to drive it. It can be said that it is more comfortable and efficient than the conventional handicapped steering cycles.

\section{REFERENCES}

[1]. Erickson, William, Camille G. Lee, and Sarah von Schrader. "2008 Disability Status Reports: United States." (2010)

[2]. Lesley, Samuel, and Lucy A. Porter. "An ergonomic wheelchair for hemiplegics." Technology and Disability 14.4 (2002): 183-189.

[3]. Cyders, Timothy J. Design of a Human-Powered Utility Vehicle for Developing Communities. Diss. Ohio University, 2008.

[4]. Fries, Richard C. Reliable design of medical devices. CRC Press, 2012

[5]. La Plante, Mitchell P., and Disability Statistics Center. "Demo-graphics of wheeled mobility device users." Conference on space requirements for wheeled mobility. Buffalo, New York: Center for Inclusive Design and Environmental Access, 2003.

[6]. Marlowe, Christie. Car Mechanic. Mason Crest, 2014.

[7]. Panero, Julius, and Martin Zelnik. Human dimension and interior space: a source book of design reference standards. Watson-Guptill, 2014.
[8]. Panero, J., and M. Zelnik. "HUMAN DIMENSION AND INTERIOR SPACE: A SOURCEBOOK OF DESIGN REFERENCE STANDARDS." (1979).

[9]. Cooper, Rory A., Rosemarie Cooper, and Michael L. Boninger. "Trends and issues in wheelchair technologies." Assistive Technology 20.2 (2008): 61-72

[10]. Khurmi, R. S., and J. K. Gupta. Machine design. S. Chand, 2005.

[11]. Bhandari, V. B. Design of machine elements. Tata McGraw-Hill Education, 2010.

[12]. Khurmi, R. S., and J. K. Gupta. Theory of machines. S. Chand, 2005.

\section{BIOGRAPHIES}

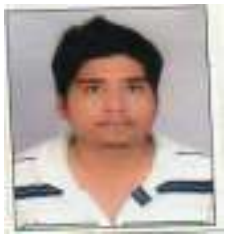

GAURAV SINGH PARIHAR completed B.E in mechanical engineering from IITM Gwalior in 2016, and presently he is an aspiring student to pursue master's in design and fabrication(mechanical) from United States of America.

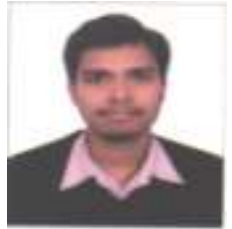

SANJAY SINGH AZAD completed B.E. in mechanical engineering from IITM Gwalior in 2012, and presently he is working as technical head in CADD PLUS TRAINING SERVICES, Gwalior. 